\title{
Cutaneous Manifestations of SARS-CoV-2 Infection
}

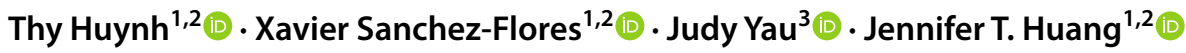

Accepted: 3 February 2022 / Published online: 5 March 2022

(c) The Author(s), under exclusive licence to Springer Nature Switzerland AG 2022

\begin{abstract}
Severe acute respiratory syndrome coronavirus 2 (SARS-CoV-2) has caused the coronavirus disease 2019 (COVID-19) pandemic, affecting people worldwide. SARS-CoV-2 infection is a multisystem disease with potential for detrimental effects on various systemic organs. It affects people of all ages with varying degrees of disease severity. Patients with SARS-CoV-2 infection commonly present with dry cough, fever, and fatigue. A clinical spectrum of skin findings secondary to SARS$\mathrm{CoV}-2$ has also been reported. The most common cutaneous patterns associated with COVID-19 are chilblain-like lesions (CBLL), maculopapular lesions, urticarial lesions, vesicular lesions, and livedoid lesions. Other skin findings secondary to SARS-COV-2 infection are erythema multiforme (EM)-like lesions and skin findings associated with multisystem inflammatory syndrome in children (MIS-C) and rarely multisystem inflammatory syndrome in adults (MIS-A). Physician awareness of skin manifestations of SARS-CoV-2 infection can help with early identification and treatment. This narrative review provides an update of various skin manifestations reported with SARS-CoV-2 infection, including clinical presentation, proposed pathogenesis, histopathology, prognosis, and treatment options.
\end{abstract}

\section{Key Points}

Common skin manifestations due to SARS-CoV-2 infection include chilblain-like lesions, maculopapular lesions, urticarial lesions, vesicular lesions, and livedoid lesions.

Other dermatologic findings secondary to SARS-CoV-2 infection include erythema multiforme-like lesions and skin findings associated with multisystem inflammatory syndrome in children and multisystem inflammatory syndrome in adults.

Clinical presentation, pathogenesis, histopathology, prognosis, and treatment options for common cutaneous manifestations of SARS-CoV-2 infections are discussed.

Jennifer T. Huang

Jennifer.Huang@childrens.harvard.edu

1 Dermatology Section, Boston Children's Hospital, 300 Longwood Avenue, Fegan 6, Boston, MA 02115, USA

2 Harvard Medical School, Boston, MA, USA

3 Tufts University School of Medicine, Boston, MA, USA

\section{Introduction}

Severe acute respiratory syndrome coronavirus 2 (SARSCoV-2) is the zoonotic agent that causes coronavirus disease 2019 (COVID-19). In December 2019, SARS-CoV-2 was first reported in Wuhan, China and has been rapidly spreading through human-to-human transmission worldwide. In March 2020, SARS-CoV-2 was declared a global pandemic by the World Health Organization. SARS-CoV-2 infection is a multisystem disease presenting with dry cough, fever, and fatigue. Other symptoms may include anosmia, arthralgia, gastrointestinal symptoms, headaches, myalgia, nasal congestion, odynophagia, and pneumonia. It affects all age groups with differing degrees of disease severity, ranging from asymptomatic carriers to patients requiring intensive care.

With the increasing number of SARS-CoV-2 cases worldwide, several dermatologic manifestations have been reported in association with SARS-CoV-2 infection. There are online registries, by the American Academy of Dermatology (AAD) and International League of Dermatological Societies (ILDS), in which skin lesions during or following SARS-CoV-2 infection can be reported to help describe the spectrum of SARS-CoV-2-related skin changes [1]. However, Recalcati was the first to report skin manifestations associated with SARS-CoV-2 [2]. The estimated incidence 
of cutaneous manifestations secondary to COVID-19 is between 4 and 20.4\% [3]. In an independent survey of 11,544 respondents, Visconti et al. reported $17 \%$ of patients infected with SARS-CoV-2 had skin manifestations as their first symptom and $21 \%$ as their only clinical sign of illness [4]. Cutaneous manifestations frequently occur during the first 4 weeks from SARS-CoV-2 symptom onset with urticarial and exanthema patterns being most common [5].

Dermatologic findings are secondary to SARS-CoV-2 binding to angiotensin-converting enzyme-2 (ACE2) receptors found in dermal blood vessels, epithelial cells of eccrine glands, and the basal layer of hair follicles [6]. Galvan-Casas et al. organized 375 cases of skin manifestations related to SARS-CoV-2 infection into the following five groups: chilblain-like lesions (CBLL), maculopapular eruptions, urticarial eruptions, vesicular eruptions, and livedo or necrosis [7]. In addition, a systematic review of 998 patients from nine different countries found that the most common cutaneous patterns were CBLL (402, 40.2\%), maculopapular lesions $(227,22.7 \%)$, urticarial lesions $(89,8.9 \%)$, vesicular lesions $(64,6.4 \%)$, and livedoid lesions $(28,2.8 \%)$ [8]. Other reported skin findings are erythema multiforme (EM)like lesions and skin findings associated with multisystem inflammatory syndrome in children (MIS-C) and rarely multisystem inflammatory syndrome in adults (MIS-A). The aim of this article is to review various skin manifestations secondary to SARS-CoV-2 infection.

\section{Methods}

Electronic searches were performed via PubMed using the following key words: COVID-19, SARS-CoV-2, skin, manifestation, chilblains, pernio, maculopapular, morbilliform, urticarial, vesicular, varicella, livedoid, erythema multiforme, target, multisystem inflammatory syndrome in children, MIS-C, pediatric inflammatory multisystem syndrome, PIMS, multisystem inflammatory syndrome in adults, and MIS-A. Articles published between September 2014 and August 2021 were included in this narrative review.

\section{Chilblain-Like/Pernio-Like Lesions}

\subsection{Clinical Presentation}

CBLL/pernio-like lesions (commonly known as 'Covid toes'), are considered to be the most common cutaneous manifestations associated with SARS-CoV-2 infection. CBLL is clinically identical to idiopathic lupus erythematosus and other autoimmune-related chilblains. Chilblains is a superficial inflammatory vascular response on acral surfaces and occurs after exposure to cold. CBLL is characterized by dusky erythematous to edematous papules, nodules, plaques or, less frequently, bullae formation (Table 1). These lesions are found on the dorsum of the toes, lateral aspects of the feet and soles, and, less commonly, fingers, and may also be seen with localized digital swelling (Fig. 1a, b).

\subsection{Pathogenesis}

SARS-CoV-2-related CBLL can be explained by tissue damage caused by immune complex depositions in blood vessels, peripheral thrombotic microangiopathy caused by elevated type-1 interferon (IFN-1) signaling, and/or secondary ischemia due to vascular damage $[9,10]$.

\subsection{Histopathology}

The histopathologic findings of CBLL show a superficial and deep perivascular lymphocytic infiltrate of predominantly $\mathrm{CD}^{+} / \mathrm{CD}^{+} \mathrm{T}$ cells with perieccrine extension, intramural lymphocytes with endothelium thickening (lymphocytic vasculitis), interface dermatitis, epidermal keratinocyte necrosis/apoptosis, papillary edema, epidermal microthrombosis, endothelialitis, and fibrin deposition in blood vessel walls $[11,12]$. Evidence of SARS-CoV-2 was shown by electron microscopy, which showed halo-like, round membranebound structures with electro-lucent centers surrounded by small spikes within the cytoplasm of endothelial cells. In addition, tubuloreticular inclusions within endothelial cells were present [12]. Direct immunofluorescence is usually negative [13].

\subsection{Prognosis/Treatment}

In a large international registry-based case series, Freeman et al. reported 318 patients identified with CBLL with laboratory testing confirming that $23(7 \%)$ patients were positive through mostly polymerase chain reaction (PCR) and/ or antibody testing [14]. Feito-Rodriguez et al. reported 37 patients with CBLL where $8.1 \%$ of all patients had SARSCoV-2-positive nasopharyngeal PCR results and $8.1 \%$ of all patients had positive SARS-CoV-2 serology results-but there was no evidence of SARS-CoV-2 on electron microscopy or PCR testing of skin samples [15]. These two studies indicate that CBLL may be a late manifestation of SARSCoV-2 infection. However, Stavert et al. performed antibody testing on 24 patients with CBLL on an average of 24 days post-onset of SARS-CoV-2 symptoms, finding that 24 (100\%) and $22(91.7 \%)$ patients tested negative for SARS$\mathrm{CoV}-2 \mathrm{IgG}$ and IgM, respectively [16]. These contradicting studies show that it is unclear when CBLL appear during the clinical course of COVID-19 infection.

If CBLL presents with other SARS-CoV-2 symptoms, it indicates an overall good prognosis, as these lesions 
Table 1 Clinical presentation and histopathology of SARS-CoV-2-associated cutaneous manifestations

\begin{tabular}{|c|c|c|}
\hline $\begin{array}{l}\text { Cutaneous manifesta- } \\
\text { tion }\end{array}$ & Clinical presentation & Histopathology \\
\hline $\begin{array}{l}\text { Chilblain-like or } \\
\text { pernio-like }\end{array}$ & $\begin{array}{l}\text { Dusky, erythematous to edematous papules, nod- } \\
\text { ules, plaques or, less frequently, bullae formation } \\
\text { on acral surfaces }\end{array}$ & $\begin{array}{l}\text { Superficial and deep perivascular lymphocytic infiltrate of pre- } \\
\text { dominantly } \mathrm{CD} 3^{+} / \mathrm{CD} 4^{+} \mathrm{T} \text { cells } \\
\text { Negative immunofluorescence }\end{array}$ \\
\hline $\begin{array}{l}\text { Maculopapular or } \\
\text { morbilliform }\end{array}$ & $\begin{array}{l}\text { Erythematous macules with areas of normal- } \\
\text { appearing skin on the trunk and extremities with } \\
\text { pruritus }\end{array}$ & $\begin{array}{l}\text { Spongiotic dermatitis with eosinophils in earlier lesions, or mixed } \\
\text { perivascular lymphocytic infiltrate with histiocytes in later } \\
\text { lesions }\end{array}$ \\
\hline Urticarial & $\begin{array}{l}\text { Migratory, pruritic, edematous, variably-sized } \\
\text { wheals within } 24 \mathrm{~h} \text { without bruising or hyperpig- } \\
\text { mentation } \pm \text { angioedema }\end{array}$ & $\begin{array}{l}\text { Perivascular lymphocytic infiltrate, scattered eosinophils, and } \\
\text { upper dermal edema with no virally induced cytopathic changes }\end{array}$ \\
\hline $\begin{array}{l}\text { Vesicular or varicella- } \\
\text { like }\end{array}$ & $\begin{array}{l}\text { Small, scattered monomorphic vesicles on the } \\
\text { trunk with mild or absent pruritus, pain, or a } \\
\text { burning sensation }\end{array}$ & $\begin{array}{l}\text { Vacuolar degeneration of basal layer, apoptotic keratinocytes, } \\
\text { mild inflammatory infiltrate, and multinucleated keratinocytes }\end{array}$ \\
\hline Livedoid & $\begin{array}{l}\text { Livedo reticularis: symmetric, lace-like dusky } \\
\text { patches forming pale-centered rings along blood } \\
\text { vessels } \\
\text { Livedo racemosa: irregular and asymmetrical } \\
\text { dusky patches along blood vessels }\end{array}$ & $\begin{array}{l}\text { Epidermal necrosis, superficial and deep dermis thrombosis } \\
\text { vasculopathy in small and medium vessels, sweat gland necro- } \\
\text { sis, mild perivascular lymphocytic infiltrate and complement } \\
\text { deposition in the vessel walls }\end{array}$ \\
\hline $\begin{array}{l}\text { Erythema multiforme- } \\
\text { like }\end{array}$ & $\begin{array}{l}\text { Target ( } 3 \text { rings) or targetoid ( } 2 \text { rings) confluent } \\
\text { macules, papules, and plaques of varying sizes } \\
\text { with hemorrhages and central crusts }\end{array}$ & $\begin{array}{l}\text { Superficial and deep perivascular perieccrine } \mathrm{CD} 3^{+} / \mathrm{CD} 4^{+} / \mathrm{CD} 8^{+} \\
\text {lymphocytic infiltrate with perieccrine involvement and scat- } \\
\text { tered vasculopathic changes }\end{array}$ \\
\hline $\begin{array}{l}\text { Multisystem inflamma- } \\
\text { tory syndrome }\end{array}$ & $\begin{array}{l}\text { Polymorphous maculopapular eruptions on the } \\
\text { trunk and flexural areas, acral erythema, extrem- } \\
\text { ity swelling and desquamation, mucositis, and } \\
\text { fissured lips }\end{array}$ & $\begin{array}{l}\text { In children: } \\
\text { Varies from biopsies with leukocytoclastic vasculitis to erythema } \\
\text { multiforme-like histopathology } \\
\text { In adults: } \\
\text { Varies from biopsies with superficial perivascular lymphocytic } \\
\text { infiltrate with rare neutrophils and extravasated erythrocytes to } \\
\text { superficial and deep perivascular and periadnexal lymphocytic } \\
\text { infiltrate histopathology }\end{array}$ \\
\hline
\end{tabular}

typically occur in mild SARS-CoV-2 cases $[14,17]$. In a case series study, Strom et al. reported that no CBLL was seen in a group of 15 hospitalized and critically ill patients with SARS-CoV-2 infection [18]. CBLL are self-limiting, lasting from 10 to 14 days and occasionally for a few months [13].

Avoiding cold temperatures and wearing protective and warm clothing, gloves, and socks will help improve CBLL. Pharmacologic treatments can also help CBLL; these include topical corticosteroids, topical and oral vasodilatory agents such as nitric oxide paste, oral calcium channel blockers, pentoxifylline, sildenafil or aspirin.

\section{Maculopapular/Morbilliform Eruptions}

\subsection{Clinical Presentation}

Maculopapular or morbilliform eruptions are frequent dermatologic manifestations secondary to SARS-CoV-2 but are nonspecific to SARS-CoV-2 and may occur with other viral infections. The prevalence of maculopapular eruptions is between 16 and $47 \%$ in patients infected with SARS-CoV-2. These lesions last for 9 days and are widespread but spare mucosa, palms, and soles [13]. Catala et al. reported 176 cases of morbilliform eruptions, which were characterized by erythematous macules with areas of normal-appearing skin on the trunk and extremities with pruritus [19].

\subsection{Pathogenesis}

Maculopapular eruptions may be caused by viral SARSCoV-2 particles and immune complex deposition that damage dermal vessels, causing lymphocytic vasculitis. These viral proteins can target Langerhans cells and keratinocytes [13].

\subsection{Histopathology}

The histopathology of maculopapular eruptions shows spongiotic dermatitis, vacuolar degeneration, as well as superficial perivascular and mixed inflammatory infiltrate [13]. The timing of biopsy is important: early-onset lesions present with epidermal spongiosis and mixed perivascular 

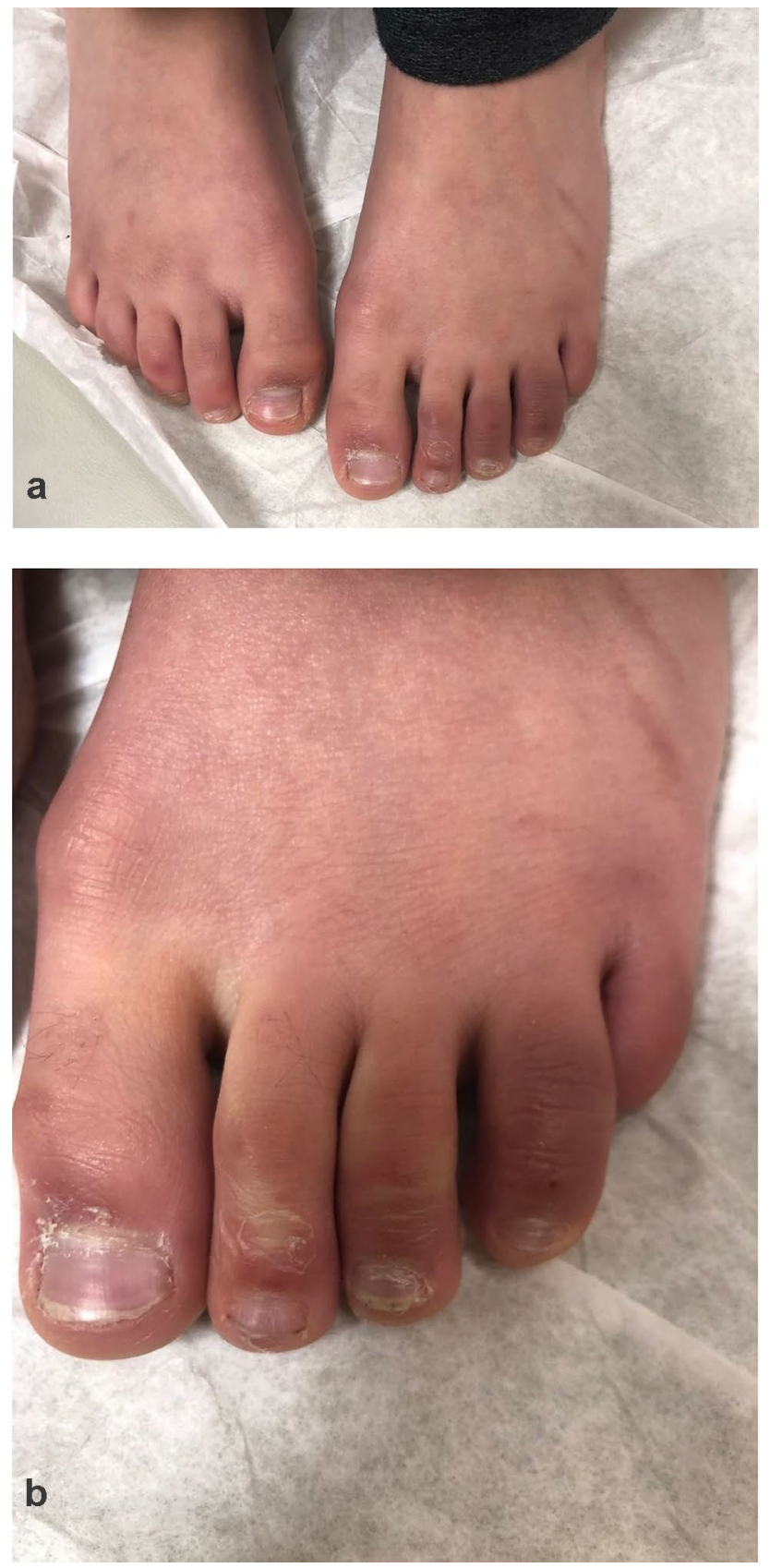

Fig. 1 a Dusky erythematous and edematous plaques involving the left second, third, and fourth toes. b Dusky erythematous and edematous plaques on the left toes

lymphocytic infiltrate consisting of eosinophils, while delayed lesions show mixed perivascular lymphocytic infiltrate with histiocytes within collagen fibers [13].

\subsection{Prognosis/Treatment}

Unlike CBLL, maculopapular eruptions are not indicative of disease severity [20]. Morey-Olive et al. reported a 6-yearold male with a positive SARS-CoV-2 PCR nasopharyngeal swab sample and developed a maculopapular rash on the trunk and extremities which self-resolved in 5 days without complications or treatments [19]. On the other hand, Hunt and Koziatek presented a 20 -year-old healthy male with fever and diffuse maculopapular eruptions on the trunk and extremities that spared the face, mucosa and eyes; he was positive for SARS-CoV-2 by PCR and later required intensive care [21]. Given the non-specificity of maculopapular rashes to SARS-CoV-2, it is important to consider other causes for these lesions, such as adverse cutaneous drug reactions from hydroxychloroquine, azithromycin, chloroquine or others.

Management of these eruptions depends on the severity of the illness. In mild cases, topical corticosteroids can be used for pruritus. In severe cases, systemic corticosteroids may be used [22].

\section{Urticarial Lesions}

\subsection{Clinical Presentation}

Urticarial lesions are also nonspecific to SARS-CoV-2 infection and may occur with other viral infections. They constitute between 4 and 19\% of SARS-CoV-2-associated dermatologic manifestations. These lesions are similar to idiopathic urticaria and predominantly affect the trunk with migratory, pruritic, edematous, variably sized wheals that resolve within 24 hours and leave no bruising or hyperpigmentation (Fig. 2). These lesions can be associated with angioedema [23].

\subsection{Pathogenesis}

The pathogenesis of urticarial lesions secondary to SARSCoV-2 infection involves the following: (i) SARS-CoV-2 binds to ACE2 receptor and enters the cell by endocytosis which disrupts the pathway for ACE2 activity, causing an increase in angiotensin II which results in reactive oxygen species formation, disruption of antioxidant and vasodilatory molecules, and ultimately complement activation [6]; (ii) SARS-CoV-2 induces basophil and mast-cell activation (which has pre-formed inflammation mediators like that of histamine), causing an inflammatory response which leads to these lesions [13].

\subsection{Histopathology}

The histopathology of urticarial lesions due to SARS-CoV-2 infection resembles that of idiopathic urticaria. These lesions demonstrate perivascular lymphocytic infiltrate, scattered eosinophils, and upper dermal edema with no virally induced cytopathic changes or intranuclear inclusions [13]. 


\subsection{Prognosis/Treatment}

Urticarial eruptions may appear as a prodromal finding with variable timing in patients infected with SARS-CoV-2. These lesions may be present before fever onset or with pyrexia and cough. For example, Rotulo et al. presented a healthy 6-year-old female with fever and pharyngodynia and was positive for SARS-CoV-2 by molecular and antigen tests; she had fleeting urticarial lesions that lasted $<24$ $\mathrm{h}$ and desquamation of the distal phalanges of the hands and feet [24]. Pagali and Parikh reported a 54-year-old female infected with SARS-CoV-2 who first presented urticarial rash on the trunk for 3 days before developing other SARSCoV-2 related symptoms [25].

These lesions are usually an indicator of severe disease. In a Spanish study of patients positive for SARS-CoV-2, $19 \%$ had urticarial lesions that lasted for an average of 6.8 days with a severe prognosis, as the mortality rate was $2 \%$ [7]. However, the presence of systemic eosinophilia is a predictor of a better prognosis [13].

It is important to take a detailed medical history as many SARS-CoV-2-positive patients take medications that may cause urticarial lesions. Symptomatic treatment for SARS-CoV-2-associated urticaria is similar to that of acute urticaria consisting of second-generation antihistamines. Low-dose oral steroids could be considered in refractory and severe cases as they target the SARS-CoV-2 cytokine storm, which help prevent mast cell activation and histamine release. Combining antihistamines with steroids can help improve urticaria lesions; however, the immunosuppressive effect of steroids can increase the risk for viral replication, thus, short-term use should be considered.

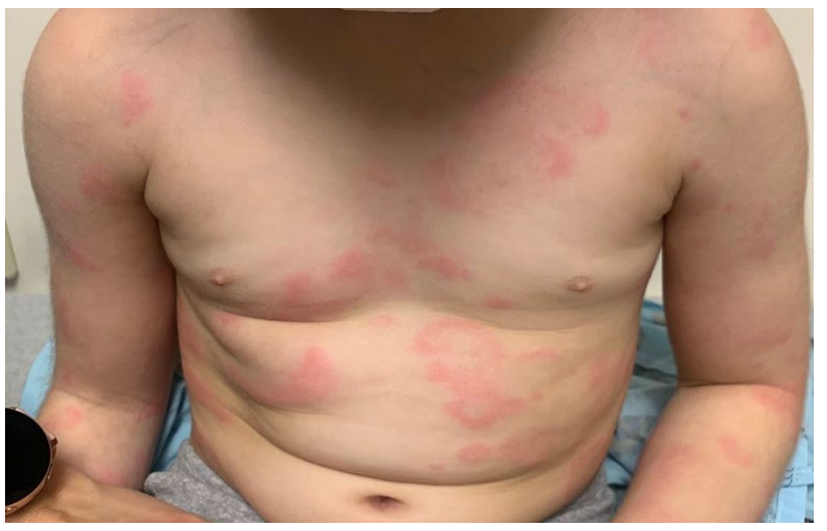

Fig. 2 Pink pruritic edematous wheals on trunk and arms

\section{Vesicular/Varicella-Like Lesions}

\subsection{Clinical Presentation}

Vesicular or varicella-like lesions secondary to SARSCoV-2 occur in both children and adults with a prevalence between 11 and $18 \%$. These lesions are characterized by small, scattered monomorphic vesicles on the trunk with mild or absent pruritus, pain, or a burning sensation. They typically occur 3 days after onset of systemic findings and resolve within 8 days without scarring.

\subsection{Pathogenesis}

Varicella-like lesions occur due to direct viral effect on keratinocytes. Evidence shows that the SARS-CoV-2 spike protein receptor, ACE2, is expressed in the basal keratinocytes [13]. SARS-CoV-2 binding to ACE-2 increases acantholysis and dyskeratosis.

\subsection{Histopathology}

The histopathology of varicella-like lesions is similar to those of viral infections. Early lesions have basal layer vacuolar degeneration as well as multinucleated and hyperchromatic keratinocytes with dyskeratotic apoptotic cells and minimal to absent inflammatory infiltrate $[13,26]$. Late lesions are similar to herpetic lesions or pseudo-herpetic Grover's disease and show intraepidermal unilocular vesicles containing multinucleated and ballooned keratinocytes with acantholytic and dyskeratotic cells as well as epidermal reticular degeneration [13].

\subsection{Prognosis/Treatment}

The prognosis of varicella-like lesions for patients infected with SARS-CoV-2 is variable. In a study of 22 Italian patients who tested positive for SARS-CoV-2, Marzano et al. reported varicella-like lesions on the trunk which developed 3 days after symptoms and lasted for 8 days without scarring; the mortality rate of this cohort was $13.6 \%$ [26]. In a case report by Genovese et al., a SARS-CoV-2-positive 8 -year-old female had multiple varicella-like lesions that developed 3 days post-onset of symptoms; these lesions resolved without treatment in 7 days [27].

There is no standard treatment for varicella-like lesions and a "wait-and-see" strategy is recommended [22]. Generally, treatment for these lesions is supportive. They selfresolve within several days without scarring. 


\section{Livedoid Lesions}

\subsection{Clinical Presentation}

The prevalence of livedo reticularis and racemosa in SARSCoV-2 patients is between 0.6 and $6 \%$ and they occur more frequently in adults than children [3]. In a case series study of 719 patients, Freeman et al. reported that livedoid reticularis represented $3.5 \%$ and livedoid racemosa represented $0.6 \%$ of all SARS-CoV-2-related cutaneous manifestations [28]. Livedoid lesions present with symmetric, lace-like dusky patches forming pale-centered rings along blood vessels. On the other hand, livedoid racemosa have irregular and asymmetrical dusky patches along blood vessels. These lesions last for an average of 9.4 days [7].

\subsection{Pathogenesis}

Livedoid lesions are the result of the activation of the complement system leading to increased coagulation resulting in microvascular injury [13].

\subsection{Histopathology}

The histopathology of these lesions includes epidermal necrosis, superficial and deep dermis thrombosis vasculopathy in small and medium vessels, sweat gland necrosis, mild perivascular lymphocytic infiltrate and complement deposition in the vessel walls $[13,29]$. Leukocytoclastic vasculitis is absent [13]. Evidence of complement deposits in the microvascular have been seen in normal-appearing skin tissue [29].

\subsection{Prognosis/Treatment}

Treatment options for livedoid lesions vary widely in pediatrics and adults. Intensive care support tends to be needed in adults with livedoid lesions [18]. In severe cases, necrosis may be present along with scabbing and sloughing of the skin.

Active non-intervention is a consideration for milder lesions, while symptomatic treatment to intensive supportive measures can be used for severe cases.

\section{Erythema Multiforme-Like/Target-Like Lesions}

\subsection{Clinical Presentation}

EM-like or target-like lesions associated with SARS$\mathrm{CoV}-2$ are hypersensitivity reactions with mucocutaneous manifestations and are seen in both children and adults. In about $90 \%$ of cases, EM lesions are usually due to infectious agents like herpes simplex virus or mycoplasma pneumonia. Other agents causing these lesions include Epstein-Barr virus, coxsackie, parvovirus, medications, and sometimes vaccines.

EM-like lesions are uncommonly reported in patients infected with SARS-CoV-2. In a case report of 22 children with CBLL, four patients presented with EM lesions, with one child who tested positive for SARS-CoV-2 by PCR testing [30]. EM-like lesions associated with SARS-CoV-2 occur on acral areas including palms, elbows, and knees in children with target ( 3 rings) or targetoid ( 2 rings) confluent macules, papules, and plaques of varying sizes with hemorrhages and central crusts (Fig. 3) [13, 30]. In older adults, these lesions are widespread with palatal macules and petechiae that spare the palms and soles [13]. They self-resolve within 1-3 weeks without scarring.

\subsection{Pathogenesis}

EM lesions are due to a hypersensitivity reaction caused by lymphocytes and cytokines targeting SARS-CoV-2 antigens at cutaneous and mucosal sites [31]. The SARS-CoV-2 EM lesions found in children may be a clinical variant of CBLL, as they are not consistent with histopathological features of true EM [30]. On the other hand, SARS-CoV-2 EM lesions found in adults may be a delayed response as these lesions appeared after recovery from SARS-CoV-2 infection.

\subsection{Histopathology}

In children, acral EM-like lesions showed superficial and deep perivascular perieccrine $\mathrm{CD} 3^{+} / \mathrm{CD}^{+} / \mathrm{CD} 8^{+}$lymphocytic infiltrate with perieccrine involvement and scattered vasculopathic changes, similar to that seen in CBLL. In addition, immunohistochemical staining was positive for SARS-CoV-2 spike protein in endothelial and epithelial cells of eccrine glands [13].

In adults, diffuse EM-like lesions were more consistent with true EM as they showed spongiosis, lymphocytic exocytosis, interface dermatitis, and focal necrotic keratinocytes [13].

\subsection{Prognosis/Treatment}

Children with EM-like lesions from SARS-CoV-2 have good prognosis with supportive treatment. Older adults with diffuse EM-like lesions tend to have severe SARS-CoV-2 clinical outcomes. 


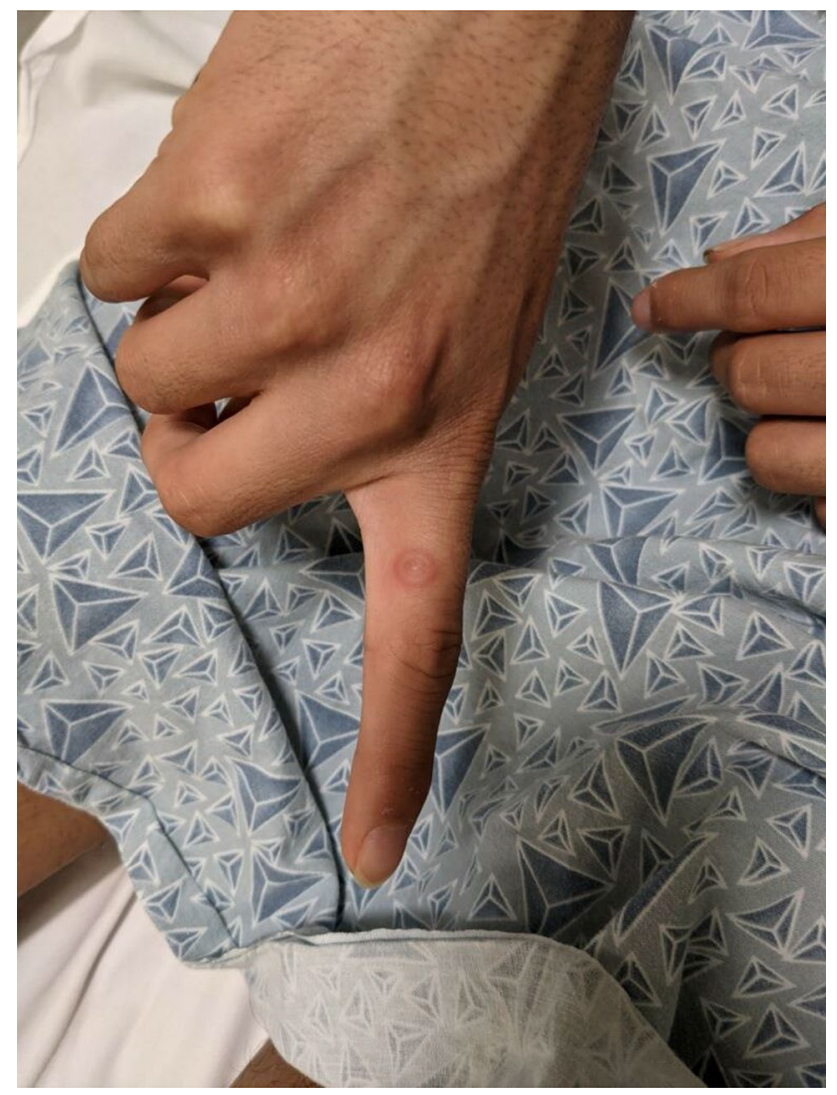

Fig. 3 Target-like papule on the index finger

\section{Multisystem Inflammatory Syndrome in Children (MIS-C)/Pediatric Inflammatory Multisystem Syndrome (PIMS)-Associated Skin Findings}

\subsection{Clinical Presentation}

In the pediatric population, there have been a number of cases of a severe hyperinflammatory condition associated with SARS-CoV-2 that share many clinical features with Kawasaki disease (KD), an acute, systemic inflammatory vasculitis that is generally diagnosed in children under 5 years caused by an exaggerated innate immune response in genetically susceptible individuals [32]. This condition, otherwise known as MIS-C in the United States or pediatric inflammatory multisystem syndrome (PIMS) in Europe, has an incidence of 11.4 cases per 100,000 people younger than 20 years of age and was first recognized in the United Kingdom in April 2020 [33]. The diagnosis criteria for KD includes a fever for $>5$ days as well as a constellation of other signs and symptoms (Table 2); however, there are $<25 \%$ of children with MIS-C that met the clinical features for KD. In a case series study of 45 children with MIS-C due to SARS-CoV-2 infection, Whittaker et al. reported that these patients were older (median age of 9 vs 2.7 years), had increased inflammatory markers like $\mathrm{C}$-reactive protein, and were more likely to have developed shock in comparison with patients with KD [34]. Patients with MIS-C secondary to SARS-CoV-2 are more likely to develop myocarditis, have elevated creatine kinase (CK) and increased cardiac injury markers, while KD patients are more likely to develop coronary artery aneurysms. In addition, patients with MIS-C due to SAR-CoV-2 infection are more likely to develop gastrointestinal symptoms like diarrhea, which was shown in $100 \%$ of children in a French prospective observational study [35].

MIS-C is a multisystemic syndrome that affects various organ systems including the brain, eyes, kidneys, and hematologic system. Skin manifestations occur in 50-76\% of patients with MIS-C [33]. Both KD and MIS-C present with similar cutaneous findings: polymorphous maculopapular eruptions on the trunk and flexural areas, acral erythema, extremity swelling and desquamation, mucositis, and fissured lips [36].

\subsection{Pathogenesis}

MIS-C associated with SARS-CoV-2 infection is due to an overactive innate immune response that has similar pathologic abnormalities in affected internal organs and skin. IgA and complement in the vessel walls have been shown by direct immunofluorescence examination, which may play a role in vasculitis [13].

\subsection{Histopathology}

Different microscopic findings have been reported for SARS-CoV-2-related MIS-C skin patterns ranging from leukocytoclastic vasculitis to erythema multiforme-like changes with nonspecific inflammatory infiltrate with mild intraepidermal neutrophils and necrotic keratinocytes [13].

\subsection{Prognosis/Treatment}

In a case series study, Whittaker et al. reported 58 pediatric patients that met criteria for MIS-C, where $26 \%$ tested positive for SARS-CoV-2 from PCR tests and $87 \%$ were positive for SARS-CoV-2 IgG, and 50\% needed intensive care [34]. Andina-Martinez et al. assessed 21 patients exhibiting mucocutaneous symptoms with 18 (86\%) patients fulfilling the criteria for MIS-C who also needed intensive care. This shows that patients exhibiting mucocutaneous symptoms secondary to SARS-CoV-2 are at a higher risk of intensive care unit admission [37].

The treatment for MIS-C secondary to SARS-CoV-2 infections depends on the severity of the symptoms. It may include supportive care, inotropic support, intravenous 
Table 2 Diagnostic criteria and treatments for multisystem inflammatory syndrome in children and Kawasaki disease

\begin{tabular}{ll}
\hline Multisystem inflammatory syndrome in children & Kawasaki disease \\
\hline $\begin{array}{l}\text { Persistent fever with elevated inflammatory markers (CRP, neutrophils) and } \\
\text { evidence of single or multi-organ dysfunction (cardiac, respiratory, renal, GI, }\end{array}$ & Fever lasting for 5 or more days \\
or neurology) & 4 of the 5 below: \\
Exclusion of other microbial or infectious causes & Bilateral conjunctival injection without exudate \\
\pm SARS-CoV-2 PCR & Erythema or cracking of the lips or erythema of the oral \\
Treatment: Supportive care, inotropic support, IVIG, aspirin, steroids, anakinra & cavity \\
and infliximab & Polymorphous exanthem \\
& Changes of peripheral extremities (edema or erythema) \\
& Acute non-purulent cervical lymphadenopathy \\
& Treatment: High-dose IVIG with aspirin \\
\hline
\end{tabular}

$C R P$ C-reactive protein, $G I$ gastrointestinal, $I V I G$ intravenous immunoglobulins, $P C R$ polymerase chain reaction

immunoglobulins (IVIG), aspirin, corticosteroids, anakinra, and infliximab [33].

\section{Multisystem Inflammatory Syndrome in Adults (MIS-A)}

\subsection{Clinical Presentation}

Although most commonly seen in pediatrics, there have been some cases of a severe hyperinflammatory condition associated with SARS-CoV-2 recognized as multisystem inflammatory syndrome in adults (MIS-A). The current five working criteria for MIS-A include severe illness requiring hospitalization for patients $>21$ years of age, positive test for current or previous SARS-CoV-2 infection in the past 12 weeks, severe dysfunction of one or more extrapulmonary organ systems, laboratory evidence of severe inflammation, and absence of severe respiratory illness [38, 39]. MISA, like MIS-C, may show polymorphic rash. Morris et al. described 16 patients meeting criteria for MIS-A and five with cutaneous manifestations, most notably mucositis, during hospital admission [38]. Additionally, So et al. described two patients with urticarial macules and plaques [40].

\subsection{Pathogenesis}

MIS-A associated with SARS-CoV-2 infection is also due to overactive innate immune activation, most likely an aberrant interferon response leading to hyperinflammation causing abnormalities in affected internal organs and skin [39]. Due to limited cases, no molecular mechanistic studies have been done.

\subsection{Histopathology}

Skin biopsy demonstrated superficial perivascular lymphocytic infiltrate with rare neutrophils and extravasated erythrocytes with negative in situ hybridization for SARSCoV-2 spike protein in a patient with urticarial macules and patches; similarly, another biopsy showed superficial and deep perivascular and periadnexal lymphocytic infiltrate with negative in situ hybridization for SARS-CoV-2 in a different patient with urticarial plaques [40].

\subsection{Prognosis/Treatment}

More than half of the patients with MIS-A required intensive care support and had fair-to-unfavorable prognosis. Some required vasopressors, extracorporeal membrane oxygenation, endotracheal intubation, and ventilation. The treatments for MIS-A secondary to SARS-CoV-2 infections include IVIG, corticosteroids, and tocilizumab, an interleukin-6 inhibitor, in addition to intensive care support when needed $[38,40]$.

\section{Other Cutaneous Manifestations}

There have been other reports of nonspecific cutaneous manifestations due SARS-CoV-2 infection. These include immune thrombocytopenic purpura (ITP), Dengue-like exanthem, pityriasis rosea-like eruptions, and acute hemorrhagic edema of infancy [41-44]. Other dermatologic manifestations that have been reported in hospitalized patients who are severely impacted by SARS-CoV-2 are acral ischemia, mucositis, dusky lesions, and bullae.

\section{Conclusion}

Many skin manifestations due to SARS-CoV-2 infection have been reported. The most common cutaneous patterns associated with COVID-19 include CBLL, maculopapular 
lesions, urticarial lesions, vesicular lesions, and livedoid lesions. EM-like lesions, MIS-C, and MIS-A are also reported but rare. Our review is limited by publication bias and dermatologists should consider the possibility of additional undescribed cutaneous findings. The timing and morphology of these reactions are diverse and thus it is difficult to identify a 'fil rouge' for cutaneous patterns associated with COVID-19. However, with the exception of MIS-C and MIS-A, cutaneous reactions occur in the setting of active infection. Thus, other infectious and non-infectious etiologies should be considered if there is no evidence of COVID19 infection. Dermatologists play an important role in the response to the SARS-CoV-2 pandemic by aiding in early recognition of skin lesions. Awareness and identification of these cutaneous manifestations can help with early diagnosis, management, and treatment of SARS-CoV-2.

\section{Declarations}

Funding None.

Conflict of interest Dr Huang serves on the Scientific Advisory Board for EllaOla. The remaining authors have no conflicts of interest.

Ethics approval Not applicable.

Consent Not applicable.

Availability of data and material Not applicable.

Code availability Not applicable.

Author contributions All authors equally contributed to this manuscript in terms of literature review and writing.

\section{References}

1. Drenovska K, Schmidt E, Vassileva S. Covid-19 pandemic and the skin. Int J Dermatol. 2020;59(11):1312-9. https://doi.org/10. 1111/ijd.15189.

2. Recalcati S. Cutaneous manifestations in COVID-19: a first perspective. J Eur Acad Dermatol Venereol. 2020;34(5):e212-3. https://doi.org/10.1111/jdv.16387.

3. Carrascosa JM, Morillas V, Bielsa I, Munera-Campos M. Cutaneous manifestations in the context of SARS-CoV-2 infection (COVID-19). Actas Dermosifiliogr. 2020;111(9):734-42.

4. Visconti A, Bataille V, Rossi N, et al. Diagnostic value of cutaneous manifestation of SARS-CoV-2 infection. Br J Dermatol. 2021;184(5):880-7. https://doi.org/10.1111/bjd.19807.

5. Gisondi P, Di Leo S, Bellinato F, Cazzaniga S, Piaserico S, Naldi L. Time of onset of selected skin lesions associated with COVID-19: a systematic review. Dermatol Ther (Heidelb). 2021;11(3):695-705. https://doi.org/10.1007/ s13555-021-00526-8.

6. Abuelgasim E, Dona ACM, Sondh RS, Harky A. Management of urticaria in COVID-19 patients: a systematic review. Dermatol Ther. 2021;34(1): e14328.
7. Galvan-Casas C, Catala A, Carretero G, Rodriguez-Jimenez P. Classification of the cutaneous manifestations of COVID-19: a rapid prospective nationwide consensus study in Spain with 375 cases. Br J Dermatol. 2020;183(1):71-7.

8. Jia JL, Kamceva M, Rao SA, Linos E. Cutaneous manifestations of COVID-19: a preliminary review. J Am Acad Dermatol. 2020;83(2):687-90.

9. Colmenero I, Hoeger PH. Vascular tumours in infants. Part II: vascular tumours of intermediate malignancy [corrected] and malignant tumours. Br J Dermatol. 2014;171(3):474-84.

10. Damsky W, Peterson D, King B. When interferon tiptoes through COVID-19: pernio-like lesions and their prognostic implications during SARS-CoV-2 infection. J Am Acad Dermatol. 2020;83(3): e269-70.

11. Kanitakis J, Lesort C, Danset M, Jullien D. Chilblain-like acral lesions during the COVID-19 pandemic ("COVID toes"): histologic, immunofluorescence, and immunohistochemical study of 17 cases. J Am Acad Dermatol. 2020;83(3):870-5.

12. Colmenero I, Santonja C, Alonso-Riano M, et al. SARS-CoV-2 endothelial infection causes COVID-19 chilblains: histopathological, immunohistochemical and ultrastructural study of seven paediatric cases. Br J Dermatol. 2020;183(4):729-37.

13. Rongioletti F, Ferreli C, Sena P, Caputo V, Atzori L. Clinicopathologic correlations of COVID-19-related cutaneous manifestations with special emphasis on histopathologic patterns. Clin Dermatol. 2021. https://doi.org/10.1016/j.clindermatol.2020.1012.1004.

14. Freeman EE, McMahon DE, Lipoff JB, et al. Pernio-like skin lesions associated with COVID-19: a case series of 318 patients from 8 countries. J Am Acad Dermatol. 2020;83(2):486-92.

15. Feito-Rodriguez M, Mayor-Ibarguren A, Camara-Hijon C, et al. Chilblain-like lesions and COVID-19 infection: a prospective observational study at Spain's ground zero. J Am Acad Dermatol. 2021;84(2):507-9.

16. Stavert R, Meydani-Korb A, de Leon D, Osgood R, Blau J, Luu T. Evaluation of SARS-CoV-2 antibodies in 24 patients presenting with chilblains-like lesions during the COVID-19 pandemic. J Am Acad Dermatol. 2020;83(6):1753-5. https://doi.org/10.1016/j. jaad.2020.08.049.

17. Marzano AV, Genovese G, Moltrasio C, et al. The clinical spectrum of COVID-19-associated cutaneous manifestations: an Italian multicenter study of 200 adult patients. J Am Acad Dermatol. 2021;84(5):1356-63.

18. Strom MA, Trager MH, Timerman D, et al. Cutaneous findings in hospitalized and critically ill patients with COVID-19: a case series of 15 patients. J Am Acad Dermatol. 2021;84(2):510-1.

19. Catala A, Galvan-Casas C, Carretero-Hernandez G, et al. Maculopapular eruptions associated to COVID-19: a subanalysis of the COVID-Piel study. Dermatol Ther. 2020;33(6): e14170.

20. Morey-Olive M, Espiau M, Mercadal-Hally M, Lera-Carballo E, Garcia-Patos V. Cutaneous manifestations in the current pandemic of coronavirus infection disease (COVID 2019). An Pediatr (Engl Ed). 2020;92(6):374-5.

21. Hunt M, Koziatek C. A case of COVID-19 pneumonia in a young male with full body rash as a presenting symptom. Clin Pract Cases Emerg Med. 2020;4(2):219-21.

22. Genovese G, Moltrasio C, Berti E, Marzano AV. Skin manifestations associated with COVID-19: current knowledge and future perspectives. Dermatology. 2021;237(1):1-12. https://doi.org/10. $1159 / 000512932$.

23. Kayiran MA, Akdeniz N. Diagnosis and treatment of urticaria in primary care. N Clin Istanb. 2019;6(1):93-9.

24. Rotulo GA, Signa S, Rosina S, Pastorino C, Bondi E, Maghnie M. Giant urticaria and acral peeling in a child with coronavirus disease 2019. J Pediatr. 2021;230:261. 
25. Pagali S, Parikh RS. Severe urticarial rash as the initial symptom of COVID-19 infection. BMJ Case Rep. 2021;14(3): e241793. https://doi.org/10.1136/bcr-2021-241793.

26. Marzano AV, Genovese G, Fabbrocini G, et al. Varicella-like exanthem as a specific COVID-19-associated skin manifestation: multicenter case series of 22 patients. J Am Acad Dermatol. 2020;83(1):280-5.

27. Genovese G, Colonna C, Marzano AV. Varicella-like exanthem associated with COVID-19 in an 8-year-old girl: a diagnostic clue? Pediatr Dermatol. 2020;37(3):435-6.

28. Freeman EE, McMahon DE, Lipoff JB, et al. The spectrum of COVID-19-associated dermatologic manifestations: an international registry of 716 patients from 31 countries. J Am Acad Dermatol. 2020;83(4):1118-29.

29. Magro C, Mulvey JJ, Berlin D, et al. Complement associated microvascular injury and thrombosis in the pathogenesis of severe COVID-19 infection: a report of five cases. Transl Res. 2020;220:1-13.

30. Torrelo A, Andina D, Santonja C, et al. Erythema multiformelike lesions in children and COVID-19. Pediatr Dermatol. 2020;37(3):442-6.

31. Janah H, Zinebi A, Elbenaye J. Atypical erythema multiforme palmar plaques lesions due to Sars-Cov-2. J Eur Acad Dermatol Venereol. 2020;34(8):e373-5.

32. Lavery M, Bouvier C, Thompson B. Cutaneous manifestations of COVID-19 in children (and adults): a virus that does not discriminate. Clin Dermatol. 2020. https://doi.org/10.1016/j.clindermatol. 2020.1010 .1020

33. Lee EH, Kepler KL, Geevarughese A, et al. Race/ethnicity among children with COVID-19-associated multisystem inflammatory syndrome. JAMA Netw Open. 2020;3(11): e2030280.

34. Whittaker E, Bamford A, Kenny J, et al. Clinical characteristics of 58 children with a pediatric inflammatory multisystem syndrome temporally associated with SARS-CoV-2. JAMA. 2020;324(3):259-69.

35. Toubiana J, Poirault C, Corsia A, et al. Kawasaki-like multisystem inflammatory syndrome in children during the covid-19 pandemic in Paris, France: prospective observational study. BMJ. 2020;369:m2094.

36. Spencer R, Closson RC, Gorelik M, et al. COVID-19 Inflammatory syndrome with clinical features resembling kawasaki disease. Pediatrics. 2020;146(3).

37. Andina-Martinez D, Nieto-Moro M, Alonso-Cadenas JA, et al. Mucocutaneous manifestations in children hospitalized with COVID-19. J Am Acad Dermatol. 2021;85(1):88-94. https://doi. org/10.1016/j.jaad.2021.03.083.

38. Morris SB, Schwartz NG, Patel P, et al. Case series of multisystem inflammatory syndrome in adults associated with SARS-CoV-2 Infection-United Kingdom and United States, March-August 2020. MMWR Morb Mortal Wkly Rep. 2020;69(40):1450-6.

39. Vogel TP, Top KA, Karatzios C, et al. Multisystem inflammatory syndrome in children and adults (MIS-C/A): case definition \& guidelines for data collection, analysis, and presentation of immunization safety data. Vaccine. 2021;39(22):3037-49. https://doi. org/10.1016/j.vaccine.2021.01.054 (epub 2021 Feb 25).

40. So NA, So J, Centkowski S, et al. Histopathologic correlation of skin manifestations of multisystemic inflammatory syndrome in adults (MIS-A) associated with SARS-CoV-2 infection [published online ahead of print, 2021 Aug 13]. JAAD Case Rep. 2021. https://doi.org/10.1016/j.jdcr.2021.06.031.10.1016/j.jdcr. 2021.06.031.

41. Bhattacharjee S, Banerjee M. Immune thrombocytopenia secondary to COVID-19: a systematic review. SN Compr Clin Med. 2020;2(11):2048-58.

42. Joob B, Wiwanitkit V. COVID-19 can present with a rash and be mistaken for dengue. J Am Acad Dermatol. 2020;82(5): e177.

43. Ehsani AH, Nasimi M, Bigdelo Z. Pityriasis rosea as a cutaneous manifestation of COVID-19 infection. J Eur Acad Dermatol Venereol. 2020;34(9):e436-7.

44. Chesser H, Chambliss JM, Zwemer E. Acute hemorrhagic edema of infancy after coronavirus infection with recurrent rash. Case Rep Pediatr. 2017;2017:5637503. 